\title{
TERMOGRAFIA MÉDICA NA AVALIAÇÃO DE RESPOSTA TERAPÊUTICA NA LEUCEMIA LINFOCÍTICA CRÔNICA
}

\author{
Letícia Telles Silva Araujoㅁ, Marcos Leal Briochi², Manoel Jacobsen Teixeira ${ }^{3}$
}

1. Pós graduanda em Termologia e Termografia Médica pela FMUSP

2. Professor Coordenador da Pós-graduação em Termografia e Termologia Médica da FMUSP

3. Professor de Neurocirurgia e da Pós-graduação em Termografia e Termologia da FMUSP

\section{RESUMO}

Leucemia linfocítica crônica (LLC), uma das doenças linfoproliferativas, é a leucemia mais comum do mundo ocidental. Foi realizado uma avaliação termográfica - exame de imagem indolor, sem contato e sem radiação, que capta a emissão de calor da superfície corporal - para avaliação pré e pós início de um tratamento quimioterápico, mostrando esse ser um método útil de avaliação de resposta ao tratamento.

Palavras-Chave: termografia; termologia; quimioterapia; leucemia linfocítica crônica.

\section{ABSTRACT}

Chronic Lymphocytic Leukemia (CLL), one of the lymphoproliferative diseases, is the most common leukemia in the western world. A thermographic asessment painless, noncontact, non-radiation imaging that captures body surface heat emission - was performed for pre and post initiation evaluation of a chemotherapy treatment, showing this to be a useful method of evaluating response to treatment.

Key Words: thermography, thermology, chemotherapy, chronic lymphocytic leukemia.

\section{DOI: http://dx.doi.org/10.18073/pajmt.2020.7.001}

\section{INTRODUÇÃO}

Leucemia linfocítica crônica (LLC) $B$ é a mais comum das doenças linfoproliferativas crônicas. Caracteriza-se por acúmulo de linfócitos clonais $\mathrm{B}$, que infiltram gânglios linfáticos, baço e medula óssea, com etiologia desconhecida e média diagnóstica 72 anos. Fatores ambientais representados pela exposição a agentes químicos e derivados do petróleo estão associados ao aumento do risco para a doença. O diagnóstico é confirmado pela presença de linfócitos clonais $>5.000 /$ ul em sangue periférico comprovado por citometria de fluxo e morfologia celular. A termografia é um método diagnóstico por imagem, sem contato, que capta e registra emissão de calor da superfície do corpo que se altera em estados patológicos. Pode ser útil para avaliar muitas doenças agudas ou crônicas, por meio 
de modificações vasculares e funcionais ${ }^{1,3,4}$.

\section{RELATO DE CASO}

Foi realizado um relato de caso em um paciente do sexo masculino, idoso, casado, 75 anos, residente no estado de Minas Gerais, portador de Leucemia Linfocítica Crônica.

Apresentava ao diagnóstico anemia, esplenomegalia, linfocitose e linfonodomegalias. A imunofenotipagem mostrava predomínio de linfócitos maduros positivos para marcadores CD19/CD5, CD20, CD22 e CD23 (ZAP 70 negativo), compatível com o diagnóstico de LLC de células $B$. Cariótipo de aspirado medular: 46, XY(20) e o mielograma estava compatível com LLC. Recebeu várias linhas de tratamento e apesar das várias abordagens apresentava refratariedade na $3^{\circ}$ linha de tratamento. Foi proposto então uma nova quimioterapia.

Nesta fase encontrava-se com o seguinte hemograma: $\mathrm{Hg}: 5,4 \mathrm{~g} \% ; \mathrm{Ht}$ : 18,9\%; vcm $=101,1$ fl.; Lg: 128.690 $\mathrm{p} / \mathrm{mm}^{3}$; N: 5150 p/mm; ;inf. 105.530 $\mathrm{p} / \mathrm{mm}^{3}$; $\mathrm{M}: 10.295 \mathrm{p} / \mathrm{mm}^{3}$; Pro-linf: $6434 \mathrm{p} / \mathrm{mm}^{3}$; Plaq: $46.000 \mathrm{p} / \mathrm{mm}^{3}$. Apresentava linfonodomegalias generalizadas (axilares, supra claviculares, pré- auriculares, cervicais).

Realizado então imagem termográfica ( fig. 1, 2 , 3 e 4), baseado em protocolos pré-estabelecidos ( International Consensus and Guidelines for Medical Thermography) , o paciente foi instruído a não realizar exercícios físicos, não ingerir substâncias estimulantes (como café, álcool ou cigarro), não tomar banho quente ou sauna, ou utilizar quaisquer substâncias químicas na pele, não ingerir álcool ou fumar nas 10 horas que antecederam a coleta.

Antes do exame termográfico, o paciente permaneceu em repouso du- rante 15 minutos em ambiente em temperatura entre 21 a $22^{\circ} \mathrm{C}$, com velocidade do ar menor que $0,2 \mathrm{~m} / \mathrm{s}$, dentro de um quarto hospitalar, para fins de aclimatação. 0 paciente foi submetido a exame termográfico com câmera termográfica FLIR modelo C2.

$\mathrm{Na}$ Termografia notou-se intensa área hiperradiante em região cervical e torácica, envolvendo as massas hiporradiantes.( figuras 2 e 4 )

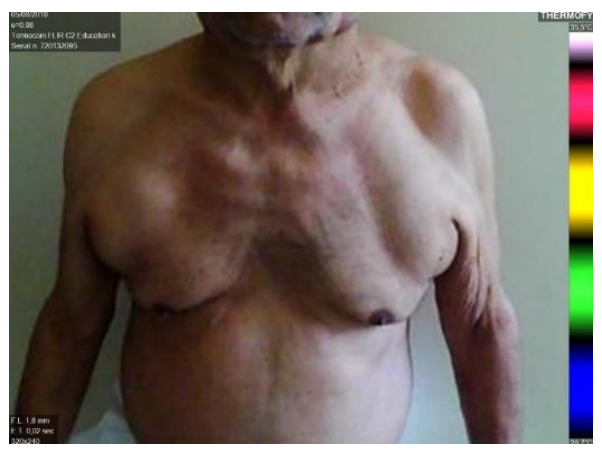

Figura 1. Imagem do paciente diagnosticado com LLC com linfonodomegalias generalizadas (axilares, supraclaviculares, pré auriculares, cervicais), previamente ao início de novo esquerda de quimioterapia.

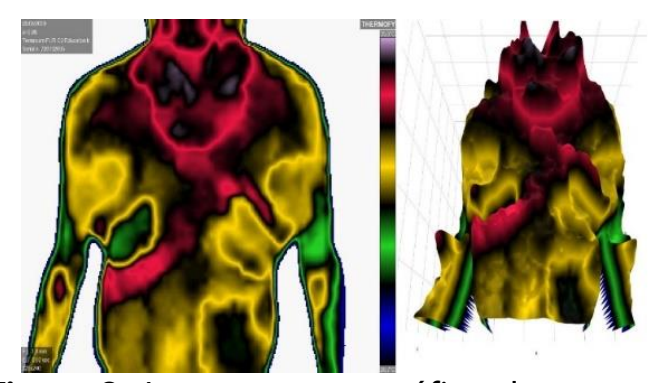

Figura 2. Imagem termográfica da mesma figura anterior, mostrando hiperrradiação em região cervical e torácica, envolvendo as massas.

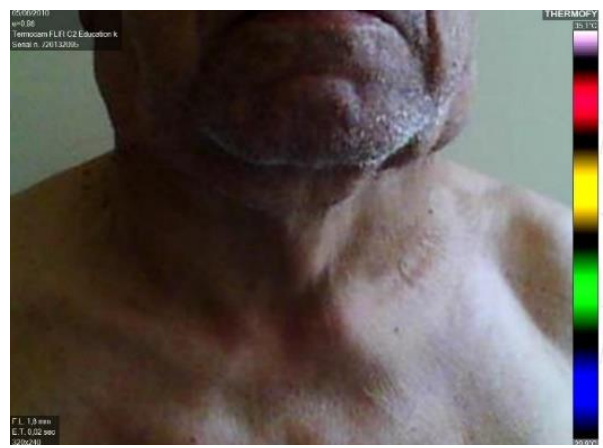

Figura 3. Imagem do paciente diagnosticado com LLC, com enfoque na área cervical, evidenciado presença de linfonodomegalias. 

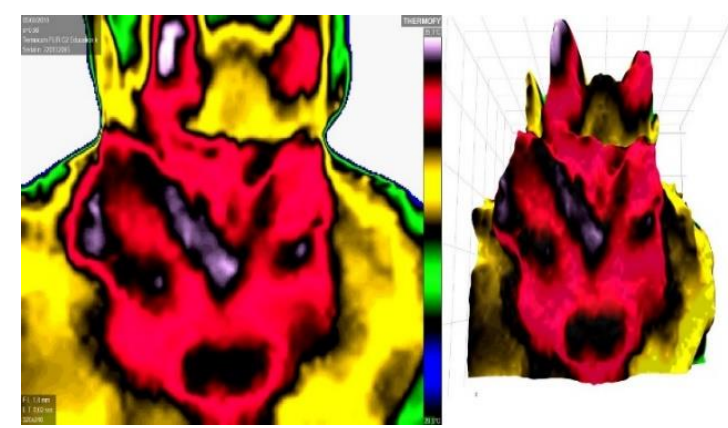

Figura 4. Imagem termográfica da mesma imagem da figura 3 , evidenciando a hiperrradiação circundando as massas.

Após 01 mês do início do tratamento, o paciente foi reavaliado com novas imagens termográficas, sendo observado redução intensa das áreas hiperrradiantes (Fig. 5, 6, 7 e 8), além de melhora clínica e laboratorial. Hemograma apresentava $\mathrm{Hg}: 7,7 \mathrm{~g} \%$; $\mathrm{Ht}: 25,7 \%$; Vcm:95,2 fl.; Lg: 17050 p/mm; N: 8354 p/mm; ; Linf: $5120 \mathrm{p} / \mathrm{mm}^{3} ; \mathrm{M}: 2728$ $\mathrm{p} / \mathrm{mm}^{3}$; Plaq: $30.000 \mathrm{p} / \mathrm{mm}^{3}$

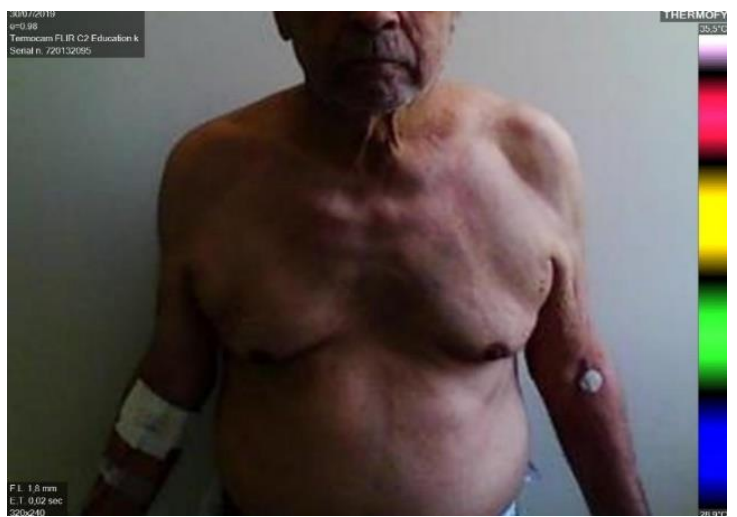

Figura 5. Imagem do paciente portador de LLC, após 01 mês do início da quimioterapia proposta, mostrando a redução das massas linfonodais.

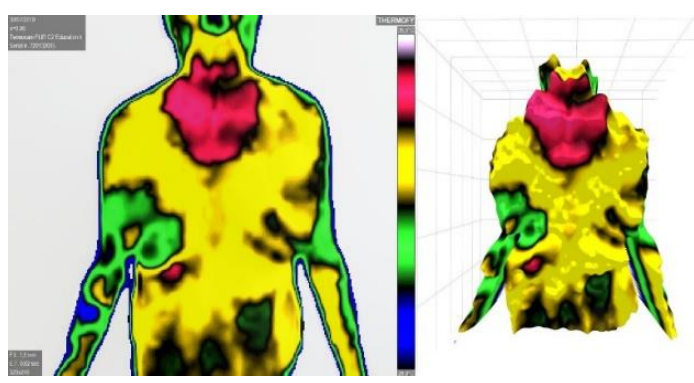

Figura 6. Imagem termográfica da mesma figura anterior (Fig. 5), evidenciando redução da hiperrradiação, previamente encontrado.

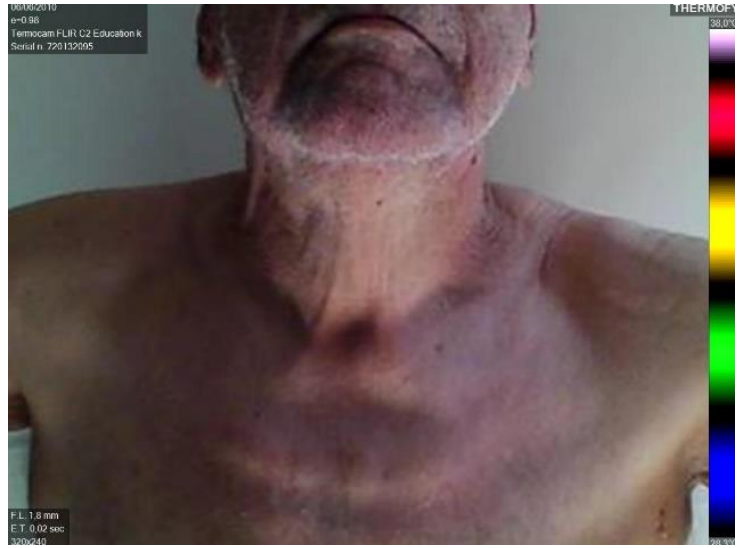

Figura 7. Imagem do mesmo paciente, com enfoque cervical, após início do tratamento quimioterápico.

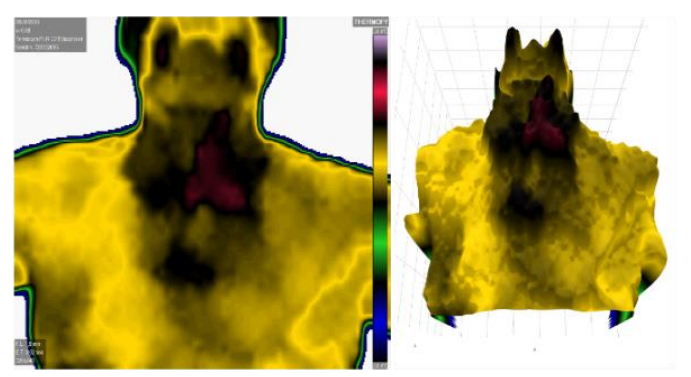

Figura 8. Imagem termográfica da mesma figura anterior, mostrando a redução da hiperrradiação.

\section{DISCUSSÃO}

Existem evidências crescentes de que a desestabilização da homeostase tecidual se origina da alteração do microambiente tumoral que não afeta apenas o comportamento das células tronco, estroma e várias células epiteliais, mas também contribui para transformar o nicho em um microambiente tumoral que facilita ainda mais o processo de transformação oncogênica, invasão de tecidos e evasão de metástases durante a progressão de um câncer. ${ }^{5}$

O programa metabólico do câncer altera os processos bioenergéticos para atender às demandas mais altas das células tumorais por produção de biomassa, síntese de nucleotídeos, homeostase redox com equilíbrio de 
NADPH . As células cancerígenas utilizam principalmente a glicólise, em oposição às células normais, que utilizam a fosforilação oxidativa ${ }^{8}$.

Esse progresso contínuo do conhecimento do envolvimento de microambiente tem levado ao desenvolvimento de estratégias terapêuticas. ${ }^{5}$

O presente trabalho avaliou, através da termografia, a resposta terapêutica de um quimioterápico em um paciente portador de Leucemia Linfocítica Crônica, que é a leucemia mais comum no mundo ocidental. ${ }^{3}$ Acomete homens com maior frequência que mulheres, em uma relação de $2: 1^{3}$. Tem uma incidência anual de 4,2 casos para cada 100.000 habitantes e em pacientes acima de 80 anos, tem incidência superior a 30 casos a cada 100.000 habitantes $^{3}$.

A grande maioria dos pacientes é assintomático ao diagnóstico, sendo a doença identificada em exames de rotina. Nos pacientes sintomáticos, os achados mais comuns são linfoadenopatias generalizadas, perda de peso e cansaço. 0 achado hematológico característico é a linfocitose persistente. Anemia e plaquetopenia também podem ocorrer ${ }^{4}$.

O quimioterápico utilizado, neste caso demonstrado, foi o ibrutinibe, um coavalente oral de primeira classe da tirosina quinase de Bruton (BTK). A BTK é essencial para a sinalização por meio dos receptores de células $B$ e receptores de quimiocinas, que as células LLC utilizam para a sobrevivência, proliferação e retorno ao tecido. Em pacientes com LLC, o ibrutinive inibiu a proliferação celular e acelerou a morte das células leucêmicas ${ }^{9}$.

O corpo humano é um sistema vivo que aquece e se resfria, procurando manter um estado de saúde, sendo a pele, um dos maiores órgãos do corpo, vital nesse processo de termorregulação, já que faz a interface entre o meio interno e o ambiente ${ }^{1,7}$.

A termorregulação do corpo humano é controlada pelo sistema nervoso neurovegetativo e o corpo humano mantém uma temperatura central dentro de uma faixa de variação muito pequena. Esta deve ser mantida constante para assegurar o funcionamento normal dos órgãos internos e cérebro ${ }^{7}$.

Todos os objetos com temperatura superior ao zero absoluto (-273 k) emitem radiação infravermelha de sua superfície. Uma vez que a emissividade da pele humana é extremamente alta ( 97,8\%), a medição da radiação infravermelha emitida pela pele pode ser convertida diretamente em valores de temperatura muito precisos ${ }^{7}$.

A detecção da temperatura das áreas da pele, por meio de um sensor térmico permitiu o avanço de uma nova técnica para investigar lesões corporais diferentes. A temperatura da pele está intimamente relacionada a estruturas anatômicas (vasculares) e funcionais ( metabólico) de uma região, servindo como pano de fundo para os diferentes padrões térmicos que são representados nos termogramas. A pele serve como termorregulador do corpo, sendo o sistema simétricos em relação a ambos os lados do corpo. Alterações dessa simetria na temperatura do corpo indicam uma possível alteração patológica?

Doenças envolvendo pescoço representam um tipo de lesão adequado para investigação termográfica, devido a facilidade de exploração da área pela termografia. Envolve estruturas profundas (vasos, glândulas, etc) que dão manifestações térmicas superficiais ${ }^{2}$.

$0 \Delta$ t entre 2 áreas permitiu avaliar a diferença de temperatura entre regiões simétricas e adjacentes, bem como ter 
uma ideia da localização das lesões linfáticas. Lesões tumorais apresentamse hiper radiantes ${ }^{2}$, com $\Delta t=3^{\circ} \mathrm{C}$.

Foi usado uma nova modalidade de imagem passiva, não invasiva, barata e reproduzível. Que detecta e analisa oscilações mínimas de temperatura e distribuição de calor no tumor. ${ }^{6}$

Explorar frequências específicas pode produzir novas informações sobre diferentes tipos de tumores, os efeitos do tratamento e o estado da doença, e será refinado em séries maiores no futuro ${ }^{6}$.

A termografia não é um teste anatômico, mas sim funcional. Os autores recomendam associar outros exames para diagnóstico definitivo e definição exata da natureza das lesões. 0 diagnóstico de LLC é feito pelas características morfológicas das células neoplásicas no sangue periférico e nos esfregaços de medula óssea (mielograma), estudos citogenéticos e moleculares ( cariótipo, FISH, imunofenotipagem de medula óssea).Tomografia computadorizada ou ultrassonografia, são métodos de imagem que podem ser usados como método de imagem para avaliação de áreas de envolvimento linfoide, como gânglios cervicais, axilares e inguinais, fígado e baço ${ }^{3,4,7}$.

\section{CONCLUSÃO}

A termografia pode ser utilizada como meio objetivo, indolor e sem radiação, de avaliar a resposta terapêutica, como quimioterapia, nos casos de leucemia linfocítica crônica.

\section{Agradecimentos}

À Denise Sabbagh Haddad - Professora do Curso de Termologia e Termografia FMUSP, à Franciele de Meneck Professora do Curso de Termologia e
Termografia FMUSP; e à Luciane Fachin Balbinot - Professora do Curso de Termologia e Termografia FMUSP

\section{REFERÊNCIAS}

1. Brioschi ML. Manual de Termografia Médica 10 ed. São Paulo: Andreoli; 2012.

2. Chiesa A, Acciarri L.The role of thermography in ORL neck lesions- Congress of Radiology in ORL (Copenhagen) - 1976

3. Eichhorst B, Robak T, Montserrat E, Ghia P, Hillmen $P$, Buske MC. Chronic lymphocytic leukaemia: ESMO Clinical Practice Guidelines for diagnosis, treatment and follow-upAnnals of Oncology 2015: 26 (Supplement 5): 78-84.

4. Zago MA, Falcão RP, Pasquini R, Tratado de Hematologia 10 ed. São Paulo: Atheneu; 2013. 1064 p.

5. Gerasimova-Chechkina E, Toner B, Marin Z, Audit B, Roux SG, Argoul F, Khalil A, Gileva O, Naimark 0 , Arneodo A. Comparative Multifractal Analysis of Dynamic Infrared Thermograms and X-Ray Mammograms Enlightens Changes in the Environment of Malignant Tumors - Front. Physiol. 2016; 7:336

6. Janicek MJ, Demetri G, Shaffer K, Fauci MA. Dynamic Infrared Imaging of Newly Diagnosed Malignant Lymphoma Compared with Gallium-67 and Fluorine-18 Fluorodeoxyglucose (FDG) Positron Emission Tomography. Technology in Cancer Research \& Treatment 2003; 2(6): 571-577.

7. Briosch ML, Teixeira MJ, Silva FM, Colman D. Princípios e Indicações da Termografia Médica. Editora Andreoli, $1^{\circ}$ edição. São Paulo, 2010.

8. Sarkova J, Hermanova I, Hlozkova K, Hararova A, Trka J. Altered Metabolism of Leukemic Cells: New Therapeutic. Opportunity International review of cell and molecular biology. 2018; 336: 93-147.

9. Burger Ja, Tedeschi A, Barr PM, Robak T, Owen C, Ghia P, Bayrei O, Hillmen P, Barlett $\mathrm{NI}$, Li J, Simpson D, Grosick S. Ibrutinib as initial therapy for patients with Chronic Lymphocytic Leukemia. N Engl J Med 2015; 373: 2425-2437 